\title{
Understanding to Enhance Efficiency of Nitrogen Uses in a Reclaimed Tidal Soil
}

\author{
Sang-Eun Lee ${ }^{1}$, Hye-Jin Kim, Mi-Suk Park, and Doug-Young Chung* \\ Dept. of Bio-environmental Chemistry, College of Agriculture and Life Sciences, \\ Chungnam National University, Daejeon 305-764, Korea. \\ ${ }^{1}$ Dept. of Plant Resources Sciences Hankyung National University Ansung 456-749 Korea
}

\begin{abstract}
In most agricultural soils, ammonium $\left(\mathrm{NH}_{4}{ }^{+}\right)$from fertilizer is quickly converted to nitrate $\left(\mathrm{NO}_{3}\right)$ by the process of nitrification which is crucial to the efficiency of $\mathbf{N}$ fertilizers and their impact on the environment. The salinity significantly affects efficiency of $\mathbf{N}$ fertilizer in reclaimed tidal soil, and the soil $\mathrm{pH}$ may influence the conversion rate of ammonium to nitrate and ultimately affect nitrogen losses from the soil profile. Several results suggest that $\mathrm{pH}$ has important effects on recovery of fall-applied $\mathrm{N}$ in the spring if field conditions are favorable for leaching and denitrification except that effects of soil $\mathrm{pH}$ are not serious under unfavorable conditions for $\mathrm{N}$ loss by these mechanisms. Soil $\mathrm{pH}$, therefore, deserves attention as an important factorin the newly reclaimed tidal soils with applying $\mathbf{N}$. However, fate of $\mathbf{N}$ studies in a newly reclaimed tidal soils have been rarely studied, especially under the conditions of saline-sodic and high $\mathrm{pH}$. Therefore, understanding the fate of nitrogen species transformed from urea treated into the reclaimed tidal soil is important for nutrient management and environmental quality. In this article, we reviewed yields of rice and fate of nitrogen with respect to the properties of reclaimed tidal soils.
\end{abstract}

Key words: Nitrogen, Reclaimed tidal soil, Soil pH, Nutrient

\section{서 언}

농업생산은 토양을 기반으로 함에 따라 농산물의 적정생 산과 생상기반을 확보하기 위하여 간척사업을 진행하는 것 은 비단 우리나라뿐만 아니라 네덜란드를 비롯하여 우리와 인접하고 있는 중국, 일본 등에서도 활발하게 진행되고 있 다. 그러나 간척지가 안정적 식량공급과 산업기지 공급 등 긍정적인 직·간접 효과를 가져왔음에도 불구하고 수자원 및 갯벌 자연생태계 파괴 등 부정적인 시각도 없지 않아 이 에 대한 대책이 시급한 실정이다 (Jung, 2007). 한편 농경 지로 이용되고 있는 대부분의 간척지는 배수불량으로 인해 대부분 논으로 이용되고 있다 (NHAES, 2002). 하지만, 생 산성을 높이기 위해 질소처리량이 일반 논보다 2 배 이상 높 지만 생산성은 관행 논에서의 평균 생산량보다 낮은 것으로 조사되었다 (Bak, 2009). 이는 염농도 뿐만 아니라 질소원 으로 가해지는 비료 종류에 따른 재배 기간 중 질소전환 과 정과 질소형태에 따른 질소이용율 증대와 관련하여 적절한 토양관리방안이 적용되지 않았기 때문인 것으로 추정된다.

우리나라의 간척지 토양은 간척지 토양내 염류는 종류에 따라 식물체의 여러 생리적 반응에 필수적으로 요구되지만 일반적으로 간척지 토양에서는 식물생육에 유해할 정도의

\footnotetext{
접수 : 2012. 11. 20 수리 : 2012. 12. 4

*연락저자 : Phone: +821052996739

E-mail:dychung@cnu.ac.kr
}

높은 농도로 존재한다 (NHAES, 2002). 현재 국내 간척지는 모래와 미사가 많고 지하수위가 높고, 배수가 불량할 뿐만 아니라 심토에 염분이 많이 집적되어 있어 제염을 실시한 후 증발산량이 강우량보다 높을 경우 모세관상승에 의해 표 토에 염분집적이 쉬워 재염화현상이 발생할 우려가 매우 높 아 작물재배 기간 중 시용한 비료성분의 상당량이 표토에 집적되기 때문에 표토의 염분농도가 증가한다 (Yoo and Lee, 1988). Han (2011)이 조사한 기존의 간척지 토양연구 결과를 살펴보면 오래된 간척지토양의 $\mathrm{pH}$ 는 중성 이하로 조사되었지만 새만금과 같은 신간척지의 $\mathrm{pH}$ 는 7 이상으로 조사되었다. 그리고 담수 시 토양의 산화환원 전위 조사 결 과를 살펴보면 간척지 토양은 환원상태에 속하는 $-200 \mathrm{mV}$ 이하로 질소질비료를 토양에 공급 시 가용화율이 감소하는 반면 암모니아 가스 등으로 손실되는 질소의 양이 증가할 것으로 추정되고 있으나 (Savant et al., 1985; Overrein and Moe, 1967) 이에 대한 연구는 매우 미미하다.

Choi et al. (2004)이 남서해안 간척지에서 토양 염농도 (저염; 0.1\%, 중염; 0.3 0.4\%) 별로 쌀 품질 향상을 위한 적 정 질소 시비량을 구명하기 위한 시험 결과 남서해안 간척 지에서 쌀 수량 및 미질 등을 고려해 볼 때, 저염 토양에서 는 $10 \mathrm{a}$ 당 $12 \mathrm{~kg}$, 중염 토양에서는 $20 \mathrm{~kg}$ 이 적당하다고 판 단했다.

최근에 이루어지고 있는 간척사업에 대해서 다양한 농업 형태로 이용되어야 함은 물론 환경을 보존할 수 있는 방향 
으로의 개발이 절실히 요구되고 있어 이에 대한 체계적인 기반 조성과 실천전략 수립을 위한 연구가 진행되어야 한 다. 지금까지 국내에서는 간척지 토양을 작물생산성이 낮은 특수토양으로 규정하여 다양한 연구가 미비한 실정이다. 간 척지 개발에 있어서 방조제 축조 등 토목분야의 간척기술은 상당한 수준으로 향상되고 있으나, 간척사업으로 형성되는 내부 간척지의 적극적인 활용방안의 수립을 위한 토양특성 조사 등 기초기술에 대한 연구는 아직까지 부족한 실정이다. 한편 국내에서 연구된 신간척지 시비방안 등에 대한 연구결 과를 조사한 바에 따르면 국내에서 간척지 토양과 관련하여 이루어진 연구는 주로 토성별 제염효과 분석, 제염과정 해 석, 제염용수량 추정, 제염 시 용수 중 염분함량의 영향 (Koo et al., 1998), 제염과 수도재배 (Im, 1970) 및 내염성 벼 품종 의 개발을 중심으로 이루어져 왔다 (Cho et al., 1992).

이와 같이 현재까지의 간척지토양에서 연구는 제염 위주 로 연구가 실시되었고 기존에 수행된 연구의 대부분이 제염 방식에 따른 작물수량검정 연구로 제한적임을 알 수 있다. 그러므로 간척지에서 수도를 비롯한 작물생산 연구는 간척 지 토양 특성에 따른 기존의 질소 시비량을 감소시키기 위한 간척지토양에서 질소와 인의 효율적 관리 방법 연구가 필요 할 것으로 생각된다. 그러므로 간척지농업에 있어서 제염을 목적으로 실시되는 담수상태에서 토양산화환원 특성과 토양 $\mathrm{pH}$ 에 따른 처리 비종 등이 결정되어야 하며 더 나아가 밭작 물 재배를 위한 토양관리방안도 함께 개발되어야 할 것으로 판단된다. 특히 지표면에서 증발산에 따른 염상승과 분포에 따른 염류집적 방지와 알카리성 상태로 존재하는 토양에 대 한 질소질 시비개선 방안이 매우 필요한 것으로 판단된다.

질소시비량과 생산성 벼 수량은 수도 품종, 토양의 생산력, 재배관리기술, 기상 및 각종 환경요인 등에 좌우된 다. 벼수확량을 증가시키기 위한 방법으로는 토양특성을 수 도의 생육에 알맞도록 유지시키는 화학적인 개량과 작토층
및 근권확대를 위한 심경, 객토 및 배수개선 등의 물리적 개 선방법이 있다. 2002년도 해창만지구 간척지구 (간척연대 33년) 시비량과 쌀생산량을 살펴보면 (Park, 2008a) 질소시 비량을 $10 \mathrm{a}$ 당 $21.9 \mathrm{~kg}$ 을 시용 시 $10 \mathrm{a}$ 당 평균 $480 \mathrm{~kg}$ 으로 전 국 평균의 약 $90 \%$ 이상이었으나 1968년도 개간된 계화도 간척지의 (간척연대 33년) 1990년과 1991년도 2년간 시비량 $\left(\mathrm{N}-\mathrm{P}_{2} \mathrm{O}_{5}-\mathrm{K}_{2} \mathrm{O}\right)$ 를 $10 \mathrm{a}$ 당 20-13-10 $\mathrm{kg}$ 처리 시 쌀수확량은 $10 \mathrm{a}$ 당 관행에서 $224 \mathrm{~kg}$, 객토구에서 가장 높은 $412 \mathrm{~kg}$ 정도 를 수확한 것으로 조사되었다. 또한 2001년도 쌀수확량은 질소시비량을 평균 $10 \mathrm{a}$ 당 $20 \mathrm{~kg}$ 처리 시 $10 \mathrm{a}$ 당 평균 $515 \mathrm{~kg}$ 정도로 조사되었다 (Park, 2008).

상기에서 살펴본 바와 같이 간척지에서 질소시비량은 일 반 논토양의 2 배 이상이나 수확량은 일반 논에서의 평균수 확량 이하이나 질소와 인의 함량이 증가할수록 수량도 증가 하는 것으로 조사되었다 (Park, 2008).

JARES (1979)에서 발표한 바에 의하면 (Table 2) 토양 염 농도별 $10 \mathrm{a}$ 당 적정 $\mathrm{N}-\mathrm{P}_{2} \mathrm{O}_{5}-\mathrm{K}_{2} \mathrm{O}$ 시비량은 고농도에서는 $28.0-8.3-10.6 \mathrm{~kg}$ 이며, 중농도에서는 $23.0-9.1-8.3 \mathrm{~kg}$, 저 농도에서는 19.3-5.7-8.2 kg로 간척지 숙답보다는 증시를 하여야 하나 염농도가 낮아질수록 감비를 하여야 한다고 제 시하였다.

NICS (1985)에서 발표한 간척지에서 벼재배에 적합한 질 소비료 종류에 대한 연구 결과를 살펴보면 (Table 3) 요소질 비료보다는 모든 처리 염농도에서 유안형태의 질소질 비료 가 수량생산성이 더 높은 것으로 조사되었다. 이는 높은 $\mathrm{pH}$ 와 환원상태에서 암모니아 형태로 손실되는 질소량이 유안 이 요소보다 적기 때문인 것으로 추정된다.

질소분시 방법에 따른 수량 생산특성을 살펴보면 밑거름 부터 최종 출수기까지 질소질 비료를 분비가 실시되면 상대 적 수도 생산수량도 증가하는 것으로 조사되었다 (Ryu, 2009a). 이는 수도재배기간 중 담수와 배수에 따른 토양의 산화환원전위 변화에 의한 질소이용효율차이에 의한 것으

Table 1. Yield of rice and fertilizer application rate at the Haechang reclaimed tidal area in 2002.

\begin{tabular}{|c|c|c|c|c|c|c|c|c|c|}
\hline \multicolumn{3}{|c|}{ Rate of fertilization } & \multicolumn{7}{|c|}{ Yield } \\
\hline $\mathrm{N}$ & $\mathrm{P}$ & $\mathrm{K}$ & Nampyung & Dongan & Junam & Elmee & Dongjin & Others & Gyehwa \\
\hline \multicolumn{10}{|c|}{ 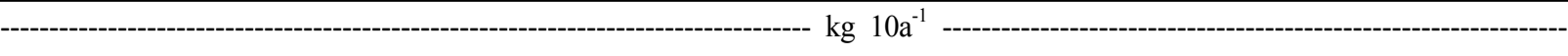 } \\
\hline 21.9 & 4.5 & 8.0 & 465 & 477 & 494 & 473 & 495 & 479 & 515 \\
\hline
\end{tabular}

Table 2. Proposed fertilizer application rates for salt levels in the reclaimed tidal soils.

\begin{tabular}{lcccccc}
\hline \hline \multirow{2}{*}{ Salt level } & \multicolumn{3}{c}{$\mathrm{N}$} & $\mathrm{P}_{2} \mathrm{O}_{5}$ & \multicolumn{2}{c}{$\mathrm{K}_{2} \mathrm{O}$} \\
\cline { 2 - 7 } & Yield & Proposed & Yield & Proposed & Yield & Proposed \\
\hline High $(0.5 \%)$ & 28 & 28.0 & 8.4 & 8.3 & 10.8 & 10.6 \\
Medium(0.3\%) & 24.1 & 23.0 & 9.8 & 9.1 & 8.5 & 8.30 \\
Low $(0.1 \%)$ & 20.4 & 19.3 & 5.8 & 5.7 & 8.3 & 8.20 \\
\hline
\end{tabular}


Table 3. Effect of fertilizer types on yield of rice under three levels of salt contents.

\begin{tabular}{lcccccc}
\hline \hline \multirow{2}{*}{ Fertilizer } & \multicolumn{5}{c}{ Levels of Salt content } \\
\cline { 2 - 7 } & Yield & Index & Yield & Index & Yield & Low \\
\cline { 2 - 7 } & ${\mathrm{kg} 10 \mathrm{a}^{-1}}$ & $\%$ & $\mathrm{~kg} 10 \mathrm{a}^{-1}$ & $\%$ & $\mathrm{~kg}^{-1} \mathrm{a}^{-1}$ & $\%$ \\
Urea & 222 & 100 & 307 & 100 & 414 & 100 \\
$\left(\mathrm{NH}_{4}\right)_{2} \mathrm{SO}_{4}$ & 238 & 107 & 339 & 110 & 440 & 106 \\
\hline
\end{tabular}

Table 4. Rice yields depending on fertilization rate of $\mathbf{N}$ for growth stages.

\begin{tabular}{|c|c|c|c|c|c|c|c|}
\hline \multicolumn{6}{|c|}{ Fertilization rate of $\mathrm{N}$ for growth stage } & \multirow{2}{*}{ Yield } & \multirow{2}{*}{ Yield index } \\
\hline Basal & Tillering & Max. Tillering & Young panicle & Boot stage & Earing stage & & \\
\hline \multicolumn{6}{|c|}{ 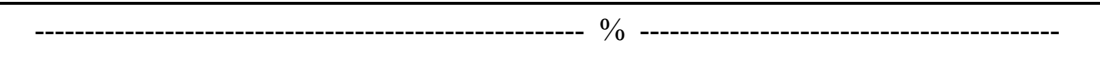 } & $\mathrm{kg} 10 \mathrm{a}^{-1}$ & $\%$ \\
\hline 40 & 30 & - & 20 & - & 10 & 348 & 100 \\
\hline 30 & 20 & 20 & 20 & - & 10 & 397 & 114 \\
\hline 20 & 20 & 20 & 20 & 10 & 10 & 424 & 122 \\
\hline 10 & 10 & 20 & 20 & 20 & 20 & 382 & 110 \\
\hline
\end{tabular}

Table 5. Amount of nitrogen absorbed by rice.

\begin{tabular}{|c|c|c|c|c|c|c|}
\hline \multirow{3}{*}{ Treatments } & \multicolumn{6}{|c|}{ N content } \\
\hline & \multicolumn{2}{|c|}{ Straw } & \multicolumn{2}{|c|}{ Brown rice } & \multicolumn{2}{|c|}{ Total } \\
\hline & $1^{\text {st }} \mathrm{yr}$ & $2^{\text {nd }} \mathrm{yr}$ & $1^{\text {st }} \mathrm{yr}$ & $2^{\text {nd }} \mathrm{yr}$ & $1^{\text {st }} \mathrm{yr}$ & $2^{\text {nd }} \mathrm{yr}$ \\
\hline & \multicolumn{6}{|c|}{ - kg 10a ${ }^{-1}$} \\
\hline Recommended & 1.94 & 2.31 & 3.99 & 2.47 & 5.93 & 4.77 \\
\hline No fertilizer & 1.62 & 1.58 & 3.50 & 2.49 & 5.12 & 4.07 \\
\hline Gypsum & 2.39 & 2.03 & 5.42 & 4.58 & 7.81 & 6.60 \\
\hline $\mathrm{Ca}(\mathrm{OH})_{2}$ & 2.69 & 1.67 & 6.68 & 3.69 & 9.37 & 5.36 \\
\hline $\mathrm{CaCO}_{3}$ & 1.52 & 2.13 & 3.61 & 2.23 & 5.14 & 4.36 \\
\hline
\end{tabular}

로 추정된다 (Table 4). 따라서 Ryu (2009a)는 염해지 논에 서 질소 흡수이용률과 쌀생산량이 증가시키기 위하여 질소 시비량을 $10 \mathrm{a}$ 당 $20 \mathrm{~kg}$ 정도로 늘리고 밑거름을 $20 \%$ 정도 사용하고 2 주일 간격으로 6 회 이상 분시하는 것을 제시하고 있다. 그리고 질소질비료는 가급적 유안, 인산질비료는 과 린산석회, 칼리질비료는 황산가리로 시용하며 $10 \mathrm{a}$ 당 인산 은 $8 \mathrm{~kg}$ 전량 기비로, 칼리는 $8 \mathrm{~kg}$ 을 기비 $3.2 \mathrm{~kg}$, 분얼비 $2.4 \mathrm{~kg}$, 수비 $2.4 \mathrm{~kg}$ 으로 3 회 분시하는 방법을 제시하였다.

\section{벼의 양분 흡수량과 수도 생육기간별 토양 $\mathrm{pH}$ 변화} $\operatorname{Kim}$ (2009)이 조사한 바에 따르면 염농도가 높은 신간척지 에 석회물질을 시용하고 2 년간 벼 재배 시 볏짚과 곡실의 질소흡수량은 2 년차에 부산석고>소석회>표준시비>탄산석 회>무비구 순으로 부산석고시용구에서 가장 많았고, 석회 물질 중에서 탄산석회시용구에서 가장 낮았다 (Table 5). 이 와 같이 부산석고시용구에서 흡수량이 많았던 원인은 치환 성 $\mathrm{Na}$ 과 염농도가 낮았던 것이 가장 큰 원인으로 추정하며,
질소비료를 요소대신 유안을 시용하였기 때문으로 생각된 다 (Vleket al., 1979).

또한 $\operatorname{Kim}$ (2009)이 조사한 결과에 따르면 개량제 시용 후 토양 중 염농도는 개량제 시용 후 57 일까지는 시용전보 다 염농도가 모두 높았으나 그 이후에는 낮아졌다. 시용 후 155 일경에 염농도는 탄산석회>부산석고>소석회의 순으로 개량제를 처리한 구가 무처리보다 $\mathrm{pH}$ 가 높은 것은 석회물 질자체의 $\mathrm{Ca}$ 함량에 기인하는 것으로 추정하였다. 한편 2 년 차의 벼 생육초기에는 개량제시용구에서 크게 낮아졌다가 유수형성기에 증가를 보였으나 수잉기인 8월 25일 이후에 는 소석회시용구를 제외하고 염정도 저하속도는 부산석고> 탄산석회>소석회>무비〉표준시비 순이었다 (Table 6). 한편 지하수위 변동도 수도재배시기에 따른 염농도 증감에 영향 을 미쳤을 것으로 추정한다. 따라서 토양개량제에 의한 제 염효과는 반드시 지하수위와 배수 조절이 필요하다.

또한 Yang (2009)이 조사한 바에 따르면 개량제 처리 후 작토중 화학성의 변화를 보면 토양산도는 관행에 비하여 생 
Table 6. Changes in soil pH depending on periods after fertilize application.

\begin{tabular}{|c|c|c|c|c|c|c|c|c|c|c|c|}
\hline \multirow{2}{*}{ Treatments } & & \multicolumn{10}{|c|}{ Periods after fertilize application (day) } \\
\hline & & 43 & 57 & 87 & 116 & 155 & 316 & 331 & 361 & 392 & 427 \\
\hline \multirow{2}{*}{ Recommended } & $\mathrm{pH}$ & 6.9 & 6.2 & 5.8 & 6.5 & 7.3 & 6.5 & 7.7 & 7.3 & 6.0 & 7.1 \\
\hline & Salt $(\%)$ & 0.48 & 0.79 & 0.72 & 0.55 & 0.35 & 0.71 & 0.69 & 0.87 & 0.86 & 0.82 \\
\hline \multirow{2}{*}{ No fertilizer } & $\mathrm{pH}$ & 6.9 & 6.7 & 6.2 & 6.8 & 7.2 & 6.2 & 7.3 & 6.1 & 6.1 & 7.2 \\
\hline & Salt $(\%)$ & 0.78 & 0.61 & 0.58 & 0.58 & 0.43 & 0.85 & 0.79 & 0.81 & 0.83 & 0.80 \\
\hline \multirow{2}{*}{ Gypsum } & $\mathrm{pH}$ & 6.7 & 7.1 & 6.2 & 6.6 & 7.8 & 6.5 & 6.0 & 7.1 & 6.7 & 6.2 \\
\hline & Salt (\%) & 1.07 & 0.96 & 0.80 & 0.32 & 0.48 & 0.39 & 0.63 & 0.65 & 0.53 & 0.44 \\
\hline \multirow{2}{*}{$\mathrm{Ca}(\mathrm{OH})_{2}$} & $\mathrm{pH}$ & 7.9 & 7.3 & 6.5 & 7.1 & 8.4 & 8.3 & 6.4 & 6.3 & 8.3 & 8.2 \\
\hline & Salt (\%) & 1.00 & 1.02 & 0.95 & 0.86 & 0.49 & 0.50 & 0.64 & 0.65 & 0.67 & 0.77 \\
\hline \multirow{2}{*}{$\mathrm{CaCO}_{3}$} & $\mathrm{pH}$ & 7.9 & 7.7 & 6.9 & 7.5 & 8.4 & 8.5 & 8.2 & 8.2 & 8.7 & 8.5 \\
\hline & Salt (\%) & 1.16 & 1.11 & 0.84 & 0.95 & 0.35 & 0.60 & 0.68 & 0.76 & 0.63 & 0.54 \\
\hline
\end{tabular}

Initial soil $\mathrm{pH}$ before fertilize application : 6.7

Table 7. Changes in soil $\mathrm{pH}$ depending on methods of treatments.

\begin{tabular}{lccccc}
\hline \hline Category & Conventional & Fresh straw & $\mathrm{CaSO}_{4}$ & Compost & Soil dressing \\
\hline $\mathrm{pH}$ & 5.7 & 5.3 & 5.3 & 5.7 & 6.2 \\
Salt contet $(\%)$ & 0.27 & 0.23 & 0.20 & 0.25 & 0.20 \\
\hline
\end{tabular}

Initial soil $\mathrm{pH}$ before fertilize application : 6.7

Table 8. Characteristics of the reclaimed tidal soils for soil series.

\begin{tabular}{|c|c|c|c|c|c|c|c|}
\hline \multirow{2}{*}{$\begin{array}{l}\text { Soil } \\
\text { series }\end{array}$} & \multirow{2}{*}{$\begin{array}{c}\text { Soil } \\
\text { Horizon }\end{array}$} & \multirow{2}{*}{ Depth } & \multicolumn{3}{|c|}{ Soil particle distribution } & \multirow{2}{*}{$\begin{array}{c}\text { Soil } \\
\text { texture }\end{array}$} & \multirow{2}{*}{$\mathrm{pH}$} \\
\hline & & & Sand & Silt & Clay & & \\
\hline & & $\mathrm{cm}$ & ----------- & $\%$ & ----------- & & $(1: 5)$ \\
\hline \multirow{2}{*}{ Hasa } & AP & $0 \sim 13$ & 94.8 & 1.8 & 3.4 & FS & 6.8 \\
\hline & $\mathrm{C} 1$ & $13 \sim 21$ & 92.4 & 3 & 4.6 & FS & 7.7 \\
\hline \multirow{2}{*}{ Yumpo } & AP & $0 \sim 10$ & 69.7 & 25.3 & 5 & FSL & 5.6 \\
\hline & $\mathrm{Clg}$ & $10 \sim 55$ & 75.9 & 20.9 & 3.2 & LFS & 5.5 \\
\hline \multirow{3}{*}{ Moonpo } & AP1 & $0 \sim 8$ & 47 & 46.5 & 6.5 & FS & 6.7 \\
\hline & AP2 & $8 \sim 18$ & 51.7 & 42 & 6.3 & FS & 8.1 \\
\hline & $\mathrm{C} 1 \mathrm{~g}$ & $18 \sim 70$ & 87 & 10.5 & 2.5 & FS & 8.1 \\
\hline \multirow{3}{*}{ Gwanghal } & AP1g & $0 \sim 12$ & 26.6 & 68.1 & 5.3 & $\mathrm{SiL}$ & 7.4 \\
\hline & $\mathrm{AP} 2 \mathrm{~g}$ & $12 \sim 22$ & 36.7 & 54.8 & 8.5 & $\mathrm{SiL}$ & 8.1 \\
\hline & $\mathrm{Clg}$ & $22 \sim 35$ & 19.3 & 60.6 & 20.1 & $\mathrm{SiL}$ & 8.0 \\
\hline \multirow{4}{*}{ Poseung } & AP & $0 \sim 10$ & 7.3 & 69.1 & 23.6 & $\mathrm{SiL}$ & 4.6 \\
\hline & B1 & $10 \sim 25$ & 4.6 & 64.3 & 31.6 & $\mathrm{SiCL}$ & 5.8 \\
\hline & $\mathrm{B} 2 \mathrm{~g}$ & $35 \sim 50$ & 5.4 & 68.2 & 26.4 & $\mathrm{SiL}$ & 6.6 \\
\hline & $\mathrm{Cg}$ & $80 \sim 140$ & 10.6 & 61.8 & 27.6 & $\mathrm{SiCL}$ & 7.1 \\
\hline
\end{tabular}

고 및 석고시용구에서 낮아진 반면 객토시용구에서는 0.5 가 높아졌다 (Table 7). 그리고 개량제 처리후 토양 염농도는 석고=객토>생고 $>$ 퇴비 $>$ 관행의 순으로 낮아졌다. 이와 같이 개량제 처리후 심경에 의한 모세관 파괴로 기층으로부터 염 분 상승을 억제함과 동시에 작토층 염분의 수직 용탈을 용 이하게 하면 간척지토양의 재염화 현상을 방지할 수 있다고 추정하였다.
토양의 이화학성과 토양내 질소 동태 $\mathrm{YoO}(2007)$ 가 조사한 간척지구별 년차적 토양산도변화를 조사한 결과를 살펴보면 토양 $\mathrm{pH}$ 는 낮아지는 것으로 조사되었으나 대부분 간척지지구에서 조사된 토양 $\mathrm{pH}$ 는 알카리에 해당하는 것으 로 조사되었다. 따라서 이러한 토양 $\mathrm{pH}$ 변화는 토양에 가해 지는 질소형태에 영향을 미쳐 작물체내로의 이동과 용탈 등 에 영향을 미칠 것으로 판단된다. 
질소는 토양 중에서 이동성이 큰 물질로서 대기권, 토양 및 생물 사이를 순환하고 있다. 토양에 존재하는 무기태 질 소는 ammonium $\left(\mathrm{NH}_{4}-\mathrm{N}\right)$ 과 nitrate $\left(\mathrm{NO}_{3}-\mathrm{N}\right)$ 의 형태가 주 를 이루고 있으며 토양질소의 대부분은 유기태질소로 가급 태질소의 급원으로서 토양비옥도면에서 중요한 인자로 알 려져 있다 (Van Cleemput et al., 1996). 한편 토양의 pH가 7.5 이상의 알카리성으로 존재할 때 토양에서는 암모니아 $\left(\mathrm{NH}_{3}\right)$ 가 생성되어 대기로 휘발된다. 상기 과정에서 생성된 수소이온은 중탄산 $\left(\mathrm{HCO}_{3}{ }^{-}\right)$에 의해 중화되어 토양은 계속 알카리성을 유지한다 (Rao and Batra. 1983). 그러나 어느 정도 시간이 경과되면 $\mathrm{NH}_{4}{ }^{+}$로부터 $\mathrm{NH}_{3}$ 로 전환과정에서 $\mathrm{HCO}_{3}{ }^{-}$가 소모되어 $\mathrm{pH}$ 는 감소하여 더 이상의 암모니아 휘발 은 발생하지 않는다. 담수상태에서 산화환원전위차는 -250 내지 $-300 \mathrm{mV}$ 정도의 범위를 나타낸다. 논과 같이 초기부 터 담수상태로 시작하는 토양에서는 식물체가 질소원을 양 분으로 이용하기 전 탈질화과정을 거치거나 아니면 용탈과 정을 통하여 손실이 발생한다. 또한 Vlek and Craswell (1989)이 조사한 $\mathrm{pH}$ 변화에 따른 암모니아 형태로의 요소손 실율을 조사한 연구 결과에 따르면 토양 $\mathrm{pH}$ 가 증가할수록 요소손실율은 지속적으로 증가한다고 하였다.

\section{요 약}

신간척지 토양 $\mathrm{pH}$ 는 7.5 이상의 알카리성 토양으로 요소 와 같은 화학비료 처리 시 휘산에 의한 손실이 증가하여 비 료효율이 저감된다. 한편 퇴비와 같은 유기태질소를 함유하 는 유기질비료를 처리하더라도 토양 내 Nitrosomonas나 Nitrobactor와 같은 미생물상이 미약하여 질산화과정이 미 약하여 실질적 유기질비료의 효과를 기대하기 어렵다. 한편 논과 같이 초기부터 담수상태로 시작하는 토양에서는 식물 체가 질소원을 양분으로 이용하기 전 탈질화과정을 거치거 나 아니면 용탈과정을 통하여 손실이 발생한다. 따라서 토 양 $\mathrm{pH}$ 가 7.5 이상으로 증가함에 따라 요소형태로 토양에 가 해진 질소원으로부터 암모니아가스 발생이 급격히 증가되 면 실질적 질소질 비료의 이용효율이 저하된다. 따라서 $\mathrm{pH}$ 7 이상의 간척지 토양에 요소를 질소원으로 처리 시 암모니 움태나 질산태 형태의 가급태 질소원은 매우 적을 것으로 추정된다. 그러므로 담수하에서의 간척지 토양의 산화환원 특성과 토양 $\mathrm{pH}$ 에 따른 처리 비종과 처리 기술개발이 반드 시 필요하다고 판단한다.

\section{Acknowledgement}

This work was carried out with the support of "Cooperative Research Program for Agriculture Science \& Technology
Development (Project No. PJ008516)” Rural Development Administration, Republic of Korea.

\section{References}

Cho, Y.K., I.S. Jo, and K.T. Um. 1992. Effects of decreasing methods of salt content in root zone on soil properties and crop grwoth at the newly reclaimed tidal soil. Korean J. Soil Sci. Fert.25:127-132.

Choi, W.Y., K.S. Lee, J.C. Ko, H.K. Park, S.S. Kim, B.K. Kim, C.K. Kim. 2004. Nitrogen fertilizer management for improving rice quality under different salinity conditions in tidal reclaimed area. Korean J. Crop Sci. 49:194-198.

Han, S.G., H.J. Kim, J.A. Song, and D.Y. Chung. 2011. Fate of nitrogen influenced by circumstances of a reclaimed tidal soils. Korean J. Soil Sci. Fert. 44:745-751.

Im, H. B. 1970. Study on the salt tolerance of rice and other crops in reclaimed soil areas. Korean J. Soil Sci. Fert. 3:35-41.

JARES. 1979. Progress report of fertilizer application rate for a reclaimed tidal soil.

Jung, Y.S. and C.R Yoo. 2007. Soil problems and agricultural water management of the reclaimed land in Korea. Korean J. Soil Sci. Fert, 40:330-348.

Jung, Y.S., and C.H. Yoo. 2007. Soil problems and agricultural water management of the reclaimed land in Korea. Korean J. Soil Sci. Fert. 40:330-348.

Kim, T.G. 2009. Types and methods of ca-fertilizer. http://blog.daum.net/ viny9364/7826871

Koo, J.W., J.K. Choi, and J.G. Son. 1998. Soil properties of reclaimed tidel lands and tidelands of western sea coast in Korea. Korean J. Soil Sci. Fert. 31:120-127.

NHAES. 2002. Agriculture in a reclaimed tidal soils in Korea. RDA, Korea.

NICS. 1985. Report-types of fertilizer for a reclaimed tidal soil. RDA, Korea.

Overrein L.N. and P.G. Moe. 1967. Factors affecting urea hydrolysis and ammonia volatilization in soil. Soil Sci. Soc. Am. Proc. 31:57-61.

Park, K.H. 2008a. Characteristics of soils for a reclaimed tidal soils at Gyehwa area-Chemical and physical properties.

Park, K.H. 2008b. http://blog.daum.net/viny9364/7826479

Rao D.L.N. and L. Batra. 1983. Ammonia volatilization from applied nitrogen in alkali soils. Plant Soil. 70:219-228

Ryu, J.H. 2008. Classification of reclaimed tidal soils. http://blog.daum.net/ viny9364/7826419. RDA.

Ryu, J.H. 2009a. http://blog.daum.net/viny9364/7826770

Ryu, J.H. 2009b. Problems in a newly reclaimed tidal soil. http://blog.daum.net/ viny9364/7826774

Ryu, J.H. 2010. Ph. D. Thesis. Chungnam National University. Savant N.K, A.F. James, and G.H. McClellan. 1985. Effect of 
soil submergence on urea hydrolysis. Soil Sci. 140:81-88

Van Cleemput, G. Hofman, and A. Vermoesen. 1996. Progress in nitrogen cycling studies. Kluwer Academic Publishers.

Vlek P.L.G, C.W. Hong, and L.J. Youngdahl. 1979. An analysis of $\mathrm{N}$ nutrition on yield and yield components for the improvement of rice fertilization in Korea. Agron J. 71:829-833

Vlek, P.L.G. and E.T. Craswell. 1979. Effect of nitrogen source and management on ammonia volatilization losses from flooded rice-soil systems. Soil Sci Soc Am J. 43:352-358
Yang, C.H. 2008. Changes in groundwater table in a reclaimed tidal soils at Saemangum.

Yoo, C.H., C.H. Yang, T.K. Kim, J.H. Ryu, J.H. Jung, S.W. Kang, J.D. Kim, and K.Y. Jung. 2007. Physico-chemical properties of paddy soil and actual farming conditions in gyehwa reclaimed tidal land. Korean J. Soil Sci. Fert. 40:109-113.

Yoo, S.H. and S.M. Lee. 1988. Laboratory study on changes in hydraulic conductivity and chemical properties of effluent of soil during desalinization. Korean J. Soil Sci. Fert. 21:3-10. 